\title{
A Rare Case of Synchronous Presentation of Acute Myeloid Leukemia and Lung Cancer
}

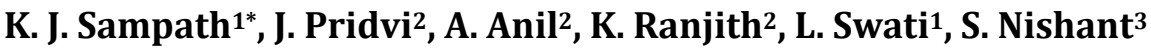 \\ ${ }^{1}$ Department of Pathology, Care Hospitals, Hitech city branch, Hyderabad, Telangana, India \\ ${ }^{2}$ Department of Oncology, Care Hospitals, Hitech city branch, Hyderabad, Telangana, India \\ ${ }^{3}$ Department of Pulmonology, Care Hospitals, Hitech city branch, Hyderabad, Telangana, India \\ Email: *dr.sampathkumar.kandala@carehospitals.com
}

How to cite this paper: Sampath, K.J., Pridvi, J., Anil, A., Ranjith, K., Swati, L. and Nishant, S. (2019) A Rare Case of Synchronous Presentation of Acute Myeloid Leukemia and Lung Cancer. Journal of Cancer Therapy, 10, 471-475.

https://doi.org/10.4236/jct.2019.106039

Received: May 20, 2019

Accepted: June 22, 2019

Published: June 25, 2019

Copyright $\odot 2019$ by author(s) and Scientific Research Publishing Inc. This work is licensed under the Creative Commons Attribution International License (CC BY 4.0).

http://creativecommons.org/licenses/by/4.0/

\begin{abstract}
Background: There are very few publications on synchronous presentation of dual malignancies in the literature. Occurrence of second malignancy in a patient with a known malignant tumor is not uncommon, though synchronous primary malignancies are unusual. Case Presentation: A 77-year-old man was diagnosed elsewhere as squamous cell carcinoma of lung came to our oncology department for further management. He underwent bone marrow evaluation with the suspicious of metastasis in view of pancytopenia. On bone marrow evaluation, found to have prominence of blasts more than $20 \%$, which were CD34 positive and CD117 positive and. Conclusion: Here we describe an unusual rare combination of synchronous presentation of acute myeloid leukemia and squamous cell carcinoma of lung.
\end{abstract}

\section{Keywords}

Synchronous Malignancy, Lung Cancer, Acute Myeloid Leukemia

\section{Introduction}

There is an increase in incidence of second primary malignancy (SPM) in patients with known malignancy due to improvement in diagnostic techniques, changes in treatment modalities and an increasing number of elderly patients. Though occurrence of metachronous primary dual malignancies is not uncommon, synchronous dual malignancies are still unusual. The exact pathophysiology for Multiple Primary Malignancies (MPM) remains unknown. Probable causative factors include ionizing radiation, increased use of organ transplant, and the increasing use of newer treatment modalities like hormonal manipulation, targeted therapies, genetic manipulation, and immunomodulators [1]. 
Chakrabarti et al. [2] have reported twelve cases of MPM against a total of 1255 cases over a period of two years. Of these, five cases were synchronous malignancies and seven cases were metachronous. Studies have reported that the relative risks of the second SPM range from 1.08 to 1.3 [3]. SPM is often missed during follow-up and is detected accidentally. Data regarding incidence, treatment and outcome of synchronous dual malignancies is still sparse. Here, we present a rare case of synchronous dual malignancies from our tertiary care centre.

\section{Case Presentation}

A 77-year-old man, who was diagnosed elsewhere with squamous cell carcinoma of lung, stage IIIA (T3N1M0), presented to our oncology department for further management. His PET scan showed right lower lobe, superior segment mass with ipsilateral mediastinal lymphadenopathy and mild plural effusion (Figure 1(a)). Biopsy of the mass showed squamous cell carcinoma of the Lung (Figure 1(b) \& Figure $1(\mathrm{c}))$. PD-L1 testing was done and the tumor proportion score of PD-L1 (FDA approved PD-L1 IHC 22C3 pharmaDx (TM) kit) immunohistochemistry
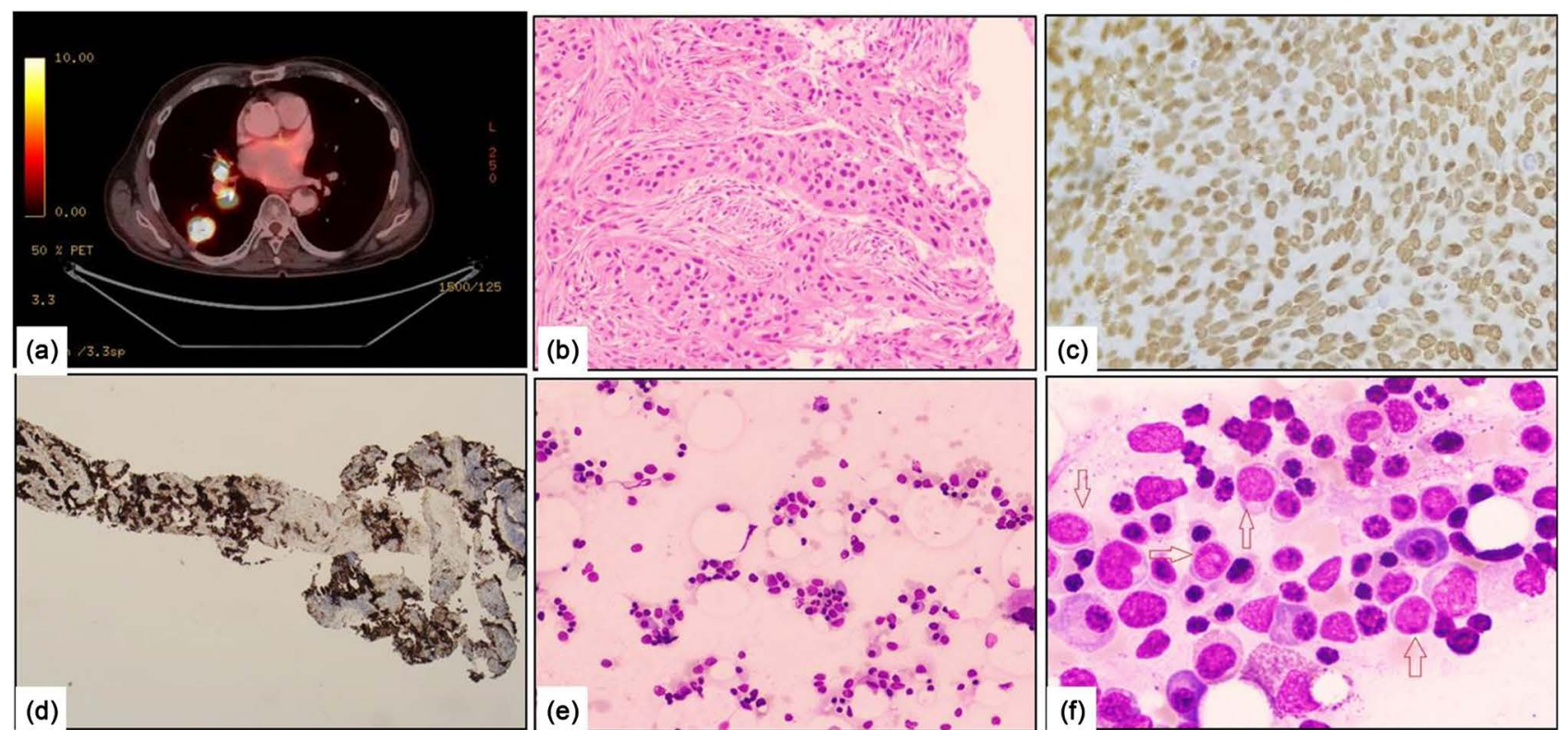

(d)
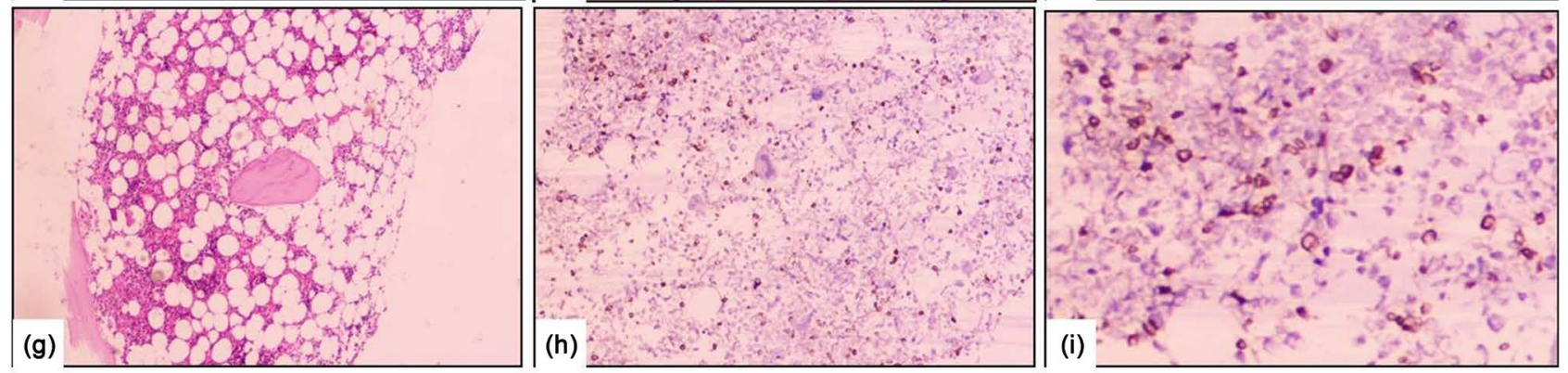

Figure 1. (a) PET scan: right lower lobe mass with ipsilateral mediastinal lymphadenopathy; (b) H\&E section of lung biopsy-moderately differentiated squamous cell carcinoma; (c) \& (d) Immunohistochemistry (IHC) on lung biopsy: P63 and PD-L1 positivity respectively; (e) \& (f) Bone marrow aspiration slides were showing prominence of blasts (highlighted by arrow); (g) H\&E section of bone marrow biopsy-scattered prominence of myeloblasts, which were highlighted by CD34 (h) and CD117 (i) markers. 
was $100 \%$ (Figure $1(\mathrm{~d})$ ). On laboratory investigations, he was found to have $\mathrm{Hb}$ of $10 \mathrm{gm} / \mathrm{dl}$, leukopenia $(2.4 \times 103 / \mathrm{ul})$ and thrombocytopenia $(10 \times 103 / \mathrm{ul})$. Other laboratory investigations include vitamin B12 $(2000 \mathrm{pg} / \mathrm{ml}$; normal range $=189$ $\mathrm{pg} / \mathrm{ml}$ to $914 \mathrm{pg} / \mathrm{ml}$ ) and folic acid $(20 \mathrm{ng} / \mathrm{ml}$; normal range $=2 \mathrm{ng} / \mathrm{ml}$ to 20 $\mathrm{ng} / \mathrm{ml})$. Bone marrow examination was done with clinical suspicion of marrow infiltration by disease.

Bone marrow examination showed prominence of blasts, which constituted $26 \%$ of marrow nucleated cells (Figure 1(e) \& Figure 1(f)). On Immunohistochemistry, these blasts were positive for CD34 (Figure 1(h)) and CD117 (Figure 1(i)) and negative for Myeloperoxidase (MPO), PanCK, CD45, CD3, CD20, Terminal deoxynucleotidyl transferase (Tdt). Immunophenotyping done on bone marrow sample, showed $22.8 \%$ myeloblasts, which were positive for CD34, CD117, CD33 and CD13 and negative for MPO, B and T cell lineage markers. Based on these findings, diagnosis of Acute myeloid leukemia with maturation (AML-M2) was made. Cytogenetic studies were normal (46XY).

The patient was advised immunotherapy with Pembrolizumab for the lung cancer as PD-L1 expression was significant and chemotherapy was not possible in view of low blood counts. Unfortunately, the patient declined to have any treatment and decided to have treatment with alternate medicine (Ayurvedic) and lost the follow-up.

\section{Discussion}

In 1879, Multiple Primary Malignancies (MPM) was first described by Billroth. The neoplasm may be limited to one organ or multiple different organs and these are classified into two categories: 1) Synchronous, in which the cancers occur at the same time or within a period of two months and 2) Metachronous, in which the cancers follow in sequence, that is, more than six months apart [4]. Metachronous primary malignancies are becoming increasing in these days because of an increase in the number of elderly cancer survivors, greater awareness and improved diagnostic modalities [5]. However, synchronous presentation of acute myeloid leukemia and solid tumor is considered to be rare.

Sheridan et al. [6] described a case report of synchronous presentation of acute myeloid leukemia and breast cancer. The cause of secondary leukemia is considered to be leukemogenic effects of topoisomerase II inhibitors or alkylating agents and abnormalities of chromosomes such as 11q23. However, no association between gene abnormalities and inherent susceptibility for leukemia could be made in the case because cytogenetic studies were not performed.

Our patient was a life-long smoker which might have been a risk factor. Possible reasons of increased risk of AML due to smoking among older subjects include decreased ability to repair DNA damage, higher exposure levels due to smoking habits that differ from those of younger subjects, and long latency for the smoking effect on AML [7]. First case series published by Ramya Vararajan et al. [5] showed twelve cases of dual malignancies, of which seven patients pre- 
sented with AML and lung cancer at different time points (metachronous) and five patients had simultaneous presentation of AML and lung cancer (synchronous). They have mentioned that tobacco's genotoxic effect would be expected to be lower on bone marrow compared to lung cancer in a patient [8]. However, other toxins [9] [10] and polymorphisms related to detoxifying enzymes [11] may have contributed to synchronous presentation of AML and lung cancer.

Di Martino et al. retrospectively studied patients treated for head and neck cancer and concluded that the treatment of a second primary is often less successful than that for the same malignancy occurring as primary. The prognosis of synchronous tumors is significantly lower when compared to malignancies of a metachronous nature. In one study, an aggressive treatment strategy was employed wherever clinically appropriate and yielded the most favorable results, with a five-year survival rate of $66.8 \%$ and $35.9 \%$ for index tumors and second primary malignancies, respectively [12].

Thus, treatment strategies in case of synchronous double malignancy depend on treating the malignancy that is more advanced first or sometimes both could be treated simultaneously [13].

\section{Conclusion}

With this case report, we want to highlight the importance of detailed evaluation of cytopenias in recently diagnosed solid organ malignancy. Cytopenia should not be overlooked as bone marrow involvement by metastasis in these patients. Till date, we could find very few publications on synchronous dual malignancies; we hope to see more case studies in the future to evaluate the causative association between acute myeloid leukemia and lung cancer.

\section{Conflicts of Interest}

The authors declare no conflicts of interest regarding the publication of this paper.

\section{References}

[1] Braakhuis, B.J., Tabor, M.P., Leemans, C.R., van der Waal, L., Snow, G.B. and Brakenhoff, R.H. (2002) Second Primary Tumors and Field Cancerization in Oral and Oropharyngeal Cancer: Molecular Techniques Provide New Insights and Definitions. Head \& Neck, 24, 198-206. https://doi.org/10.1002/hed.10042

[2] Chakrabarti, S., Chakrabatri, P.R., Desai, S.M., Agarwal, D., Mehta, D.Y. and Somanath, S. (2015) Spectrum of Second Primary Malignant Neoplasms in Central India: Case Series from a Tertiary Care Centre. The Nigerian Postgraduate Medical Journal, 22, 233-236. https://doi.org/10.4103/1117-1936.173975

[3] Curtiz, R.E., Freedom, D.M., Ron, E., Ries, L.A., Hacker, D.G., Edwards, B.K., et al. (2006) New Malignancies among Cancer Survivors: SEER Cancer Registries, 1973-2000. National Cancer Institute.

[4] Howe, H.L. (2003) A Review of the Definition for Multiple Primary Cancers in the United States. Workshop Proceedings from December 4-6, 2002, in Princeton New Jersey. Springfield, IL. 
[5] Varadarajan, R., Ford, L.A., Sait, S.N.J., Block, A.M.W., Barcos, M., Wallace, P.K., et al. (2009) Metachronous and Synchronous Presentation of Acute Myeloid Leukemia and Lung Cancer. Leukemia Research, 33, 1208-1211. https://doi.org/10.1016/j.leukres.2008.12.016

[6] Sheridan, W.P., Ellims, P.H., Hancock, W.W. and Forster, D.C. (1984) Simultaneous Occurrence of Acute Myeloid Leukemia and Carcinomatosis. British Journal of Haematology, 58, 199-200. https://doi.org/10.1111/j.1365-2141.1984.tb06072.x

[7] Sandler, D.P., Shore, D.L., Anderson, J.R., et al. (1993) Cigarette Smoking and Risk of Acute Leukemia: Associations with Morphology and Cytogenetic Abnormalities in Bone Marrow. Journal of the National Cancer Institute, 85, 1994-2003. https://doi.org/10.1093/jnci/85.24.1994

[8] Lichtman, M.A. (2007) Cigarette Smoking, Cytogenetic Abnormalities, and Acute Myelogenous Leukemia. Leukemia, 21, 1137-1140. https://doi.org/10.1038/sj.leu.2404698

[9] Hecht, S.S., Abbaspour, A. and Hoffman, D. (1988) A Study of Tobacco Carcinogenesis. XLII. Bioassay in A/J Mice of Some Structural Analogues of Tobacco-Specific Nitrosamines. Cancer Letters, 42, 141-145.

https://doi.org/10.1016/0304-3835(88)90251-0

[10] Snyder, R. (2002) Benzene and Leukemia. Critical Reviews in Toxicology, 32, 155-210. https://doi.org/10.1080/20024091064219

[11] Crane, M.M., Strom, S.S., Halabi, S., Berman, E.L., Fueger, J.J., Spitz, M.R., et al. (1996) Correlation between Selected Environmental Exposures and Karyotype in Acute Myelocytic Leukemia. Cancer Epidemiology, Biomarkers \& Prevention, 5, 639-644.

[12] Di Martino, E., Sellhaus, B., Hausmann, R., Minkenberg, R., Lohmann, M. and Esthofen, M.W. (2002) Survival in Second Primary Malignancies of Patients with Head and Neck Cancer. The Journal of Laryngology \& Otology, 116, 831-838. https://doi.org/10.1258/00222150260293664

[13] Agarwal, R. (2007) Synchronous Dual Malignancy; Successfully Treated Cases. Journal of Cancer Research and Therapeutics, 3, 153-156.

https://doi.org/10.4103/0973-1482.37408 